\title{
Combined Use of Systems Methodologies in Creative Managing the Problem Situations: Key Features, Benefits and Challenges
}

\author{
Dejana Zlatanović \\ Faculty of Economics, University of Kragujevac, Republic of Serbia
}

\section{Abstract}

Management problems in contemporary enterprises should be, according to their increasing complexity and diversity, observed and explored as the management problem situations, that is the systems of problems. Creative dealing with these complex, dynamic and ambiguous problem situations implied the development of a great variety of systems approaches to problem solving, i.e. systems methodologies for problem situations structuring. Since no methodology is able to explore all aspects of the complex problem situations in enterprises, the topic of the paper is combined use of systems methodologies in creative managing the problem situations. The goal of this paper is to highlight the key features, benefits and challenges of combining the systems methodologies in creative managing the problem situations in enterprises. Therefore, research in the paper is relied on Critical Systems Thinking as a conceptual framework for combined use of systems methodologies. Despite the limitations of combining the systems methodologies, methodologically appropriate combined use of systems methodologies enables improvement of managing the problem situations in contemporary enterprises.

Keywords: management problem situations, systems methodologies for problem situations structuring, critical systems thinking, combined use of systems methodologies, improvement of managing the problem situations in enterprises JEL classification: M10

\section{Introduction}

As a result of simultaneous influences of numerous and various economic, organizational, sociological, psychological, technical, political determinants, management problems in contemporary enterprises should be observed and explored as the complex, dynamic, interactive, ambiguous manageable systems of problems (Jackson, 2003; Petrović, 2012). Creative dealing and managing the problem situations imply using the different systems methodologies for problem situations structuring. By critical evaluation and identifications of the strengths and weaknesses of different systems methodologies it is found that these methodologies should be combined. According to critical awareness as the relevant commitment of Critical Systems Thinking (Jackson, 1991; 1994; 2003; 2010), it can be concluded that no methodology is able to explore all aspects of complex problem situations in enterprises. It further implies combined use of systems methodologies. Therefore, the goal of this paper is to highlight the key features, benefits and challenges of combining the systems methodologies in creative managing the problem situations in enterprises. Combined use of systems methodologies is established within the Critical Systems Thinking (CST) as a context, i.e. conceptual framework for combining them. 
Respecting the above-mentioned, the paper is structured as is follows: First of all, the key features and principles of CST as a conceptual framework for combining the systems methodologies are presented. Then, some of the relevant issues in combined use of systems methodologies are selected and briefed. Finally, the key benefits and limitations of combining the systems methodologies are emphasized.

\section{A conceptual framework for combining the systems methodologies}

As a relevant paradigm in contemporary systems thinking, Critical Systems Thinking (CST) is suitable for the systems characterized by different power of participants, conflicts, as well as coercion. In this paper, CST is considered as an appropriate conceptual framework for combining the systems methodologies. CST is aimed to support holistic managing of the diversity of systems approaches, that is, to reveal the ways of appropriate combined use of diverse systems theories, methodologies, methods and models in order to respond to complexity, change and diversity of problem situations in contemporary organizations (Jackson, 2010).

According to Jackson $(1991,1994)$ CST is based on the following commitments: critical awareness, social awareness, dedication to human emancipation, complementarism at the level of methodology and complementarism at the theoretical level. In the given context, of relevant importance is critical awareness that is related to the fact that all systems methodologies have certain strengths and weaknesses and that it is necessary to understand these and use each methodology in the particular circumstances most appropriate for it. Another result of critical awareness is that systems methodologies should be combined in order to address different aspects of the complex problem situations.

The commitment to social awareness refers to consideration of organizational and societal climate that determine popularity of particular systems approaches, as well as consideration of the social consequences of using them.

Dedication to human emancipation as a relevant commitment of CST is concerned with enabling the conditions in which all individuals can develop their own potentials and in which the quality of life and work can be increased.

Complementarism at the level of methodology, i.e. complementary or combined use of various systems methodologies, methods and models is a result of critical awareness. It requires a meta-methodology that can help in choosing the methodologies most appropriate for problem situation under consideration. One of the first representations of methodological complementarism is the System of Systems Methodologies. Apart from the System of Systems Methodologies, Total Systems Intervention is developed and aimed to enable appropriate and coherent combining the systems methodologies from different paradigms.

Finally, complementarism at the theoretical level is inseparable from complementarism at the methodological level. Different systems approaches express different rationalities stemming from alternative theoretical assumptions. These alternative positions must be respected and methodologies to which they give rise developed in partnership (Jackson, 1994, p. 225). This argument is supported by linking the different systems approaches with different human interests - technical, practical and emancipatory - as identified by Habermas (1972).

However, in Jackson's later contributions (2003; 2010) following three pillars or commitments of CST have been distinguished: critical awareness, improvement and pluralism. In fact, the development of CST can be linked primarily to two related sources: a growing critical awareness of the strengths and weaknesses of individual 
systems approaches and an appreciation of the need for pluralism in systems thinking (Jackson, 2010, p. 134). Therefore, one can conclude that development of CST is inseparable from the pluralism. In the broadest sense, pluralism can be understood as "a respect for different perceptions and interpretations of the management problems in organizations, as well as an appropriate combined use of various methodologies, methods, techniques and models in problem situations structuring and problem solving (Petrović, 2012, p. 797).

In order to CST realize its full potential, numerous issues should be considered at the level of methods, models and techniques, as well as at the level of methodology and meta-methodology. Some of these issues in combining the systems methodologies are further selected and briefed.

\section{Briefly about the selected issues in combining the systems methodologies}

The essence of multimethodology, i.e. combining the systems methodologies is to employ more than one methodology or parts of methodologies within single intervention. Therefore, the first issue that should be considered is whether more than one methodology is used or not. Consequently, Mingers (1997a, pp. 7-8) as well as Mingers and Brocklesby (1997) distinguished following situations: First situation is methodological isolationism where only one methodology is used. Paradigmatic isolationism is a situation where several methodologies from the same paradigm are used, but not in the same intervention. Furthermore, complete methodologies from the same paradigm can be combined in the same intervention - for example, combining Organizational Cybernetics and System Dynamics - SD (e.g. Schwaninger and Peréz Ríos, 2008). Also, the particular parts of the methodology may be combined with a complete methodology (for example using the cognitive maps within Soft Systems Methodology - SSM). In addition, one can combine the parts of particular systems methodologies from the same paradigm (for example, combining the cognitive maps with root definitions and conceptual models of SSM) (e.g. Ormerod, 1997).

The situation is much more complex when methodologies from different paradigms are used in combination. In that case, there are the following possibilities: Firstly, employment of systems methodologies within the System of systems Methodologies that implies using one systems methodology as a dominant and another methodology as a supportive or within Total Systems Intervention in which different methodologies may be used within the same intervention to deal with different aspects of the problem situation"(e.g. Clarke and Lehaney, 2000)". Then, one complete systems methodology can be combined with the parts of another methodology (for example, using the Viable System Model or System Dynamics' causal loop diagrams within Soft Systems Methodology)(e.g. Kinloch et al., 1997). Finally, the most complex situation is the one in which the parts of methodologies from different paradigms are used together within particular problem situation (for example, cognitive maps with System Dynamics' models (e.g. Bennet et al., 1997) or rich pictures, root definitions and conceptual models as the key methodological tools of SSM with System Dynamics' causal loop diagrams and stock and flow diagrams (e.g. Zlatanović, 2015, pp. 208-244).

One of the key issues in combined use of systems methodologies is how one can choose appropriate combination of methodologies in the particular intervention. Therefore, a relevant framework for mapping methodologies is developed in order 
to deal with different perspectives of the problem situation and to identify methodologies that can be used in that situation (Table 1).

Table 1

A Framework for Mapping Methodologies

\begin{tabular}{|l|l|l|l|l|}
\hline & Appreciation of & \multicolumn{1}{|c|}{ Analysis of } & \multicolumn{1}{|c|}{ Assessment of } & \multicolumn{1}{|c|}{ Action to } \\
\hline Social & $\begin{array}{l}\text { social practices, } \\
\text { power relations }\end{array}$ & $\begin{array}{l}\text { distortions, } \\
\text { conflicts, interests }\end{array}$ & $\begin{array}{l}\text { ways of altering } \\
\text { existing structures }\end{array}$ & $\begin{array}{l}\text { generate } \\
\text { empowerment } \\
\text { and enlightenment }\end{array}$ \\
\hline Personal & $\begin{array}{l}\text { individual } \\
\text { beliefs, } \\
\text { meanings, } \\
\text { emotions }\end{array}$ & $\begin{array}{l}\text { differing } \\
\text { perceptions and } \\
\text { personal } \\
\text { rationality }\end{array}$ & $\begin{array}{l}\text { alternative } \\
\text { conceptualisations } \\
\text { and constructions }\end{array}$ & $\begin{array}{l}\text { generate } \\
\text { accommodation } \\
\text { and consensus }\end{array}$ \\
\hline Material & $\begin{array}{l}\text { physical } \\
\text { circumstances }\end{array}$ & $\begin{array}{l}\text { underlying } \\
\text { causal structure }\end{array}$ & $\begin{array}{l}\text { alternative physical } \\
\text { and structural } \\
\text { arrangements }\end{array}$ & $\begin{array}{l}\text { select and } \\
\text { implement best } \\
\text { alternatives }\end{array}$ \\
\hline
\end{tabular}

Source: Mingers (2000, p. 684)

As one can see from the Table 1, the framework for mapping methodologies is characterized by multidimensionality of the problem situation, i.e. by three different aspects or 'worlds'- social, personal and material, as well as by different phases of intervention - appreciation, analysis, assessment and action. This framework can help to identify the strengths of particular systems methodologies which are the basis for their mixing.

Decomposing methodologies is also very important issue in combined use of systems methodologies. It is based on idea that some techniques or methods can be detached from one methodology and used in another. Linking the parts of particular methodologies requires that "methodologies be decomposed in some systematic ways to identify detachable elements and their functions or purposes (Mingers, 1997b, p. 434).

Mingers (1997b, p.435) outlined the framework representing the decomposition of Soft Systems Methodology to show possible disconnection of techniques. Accordingly, decomposition of Interactive Planning, as another example of possible decomposing the systems methodology, is presented in the Figure 1. As Figure 1 shows, each of stages of Interactive Planning has particular techniques that help to accomplish them (e.g. analyses 1, 2 and 3 for formulating the problem situation, i.e. for mess formulating). Figure 1 also shows how techniques stemming from alternative methodology can be imported into this methodology (e.g. rich pictures of SSM as a possible complement to analyses $1,2,3)$. It is very important to emphasize that decomposition of methodology should be done carefully, i.e. the theoretically uncontrolled employment of tools must not be allowed. It further means that at any moment during an intervention the use of the tools in combination should be invested with a particular theoretical rationale guaranteed because they are employed according to the rules of a methodology serving a particular paradigm (Jackson, 2001, p. 239). 
Figure 1

Decomposition of Interactive Planning

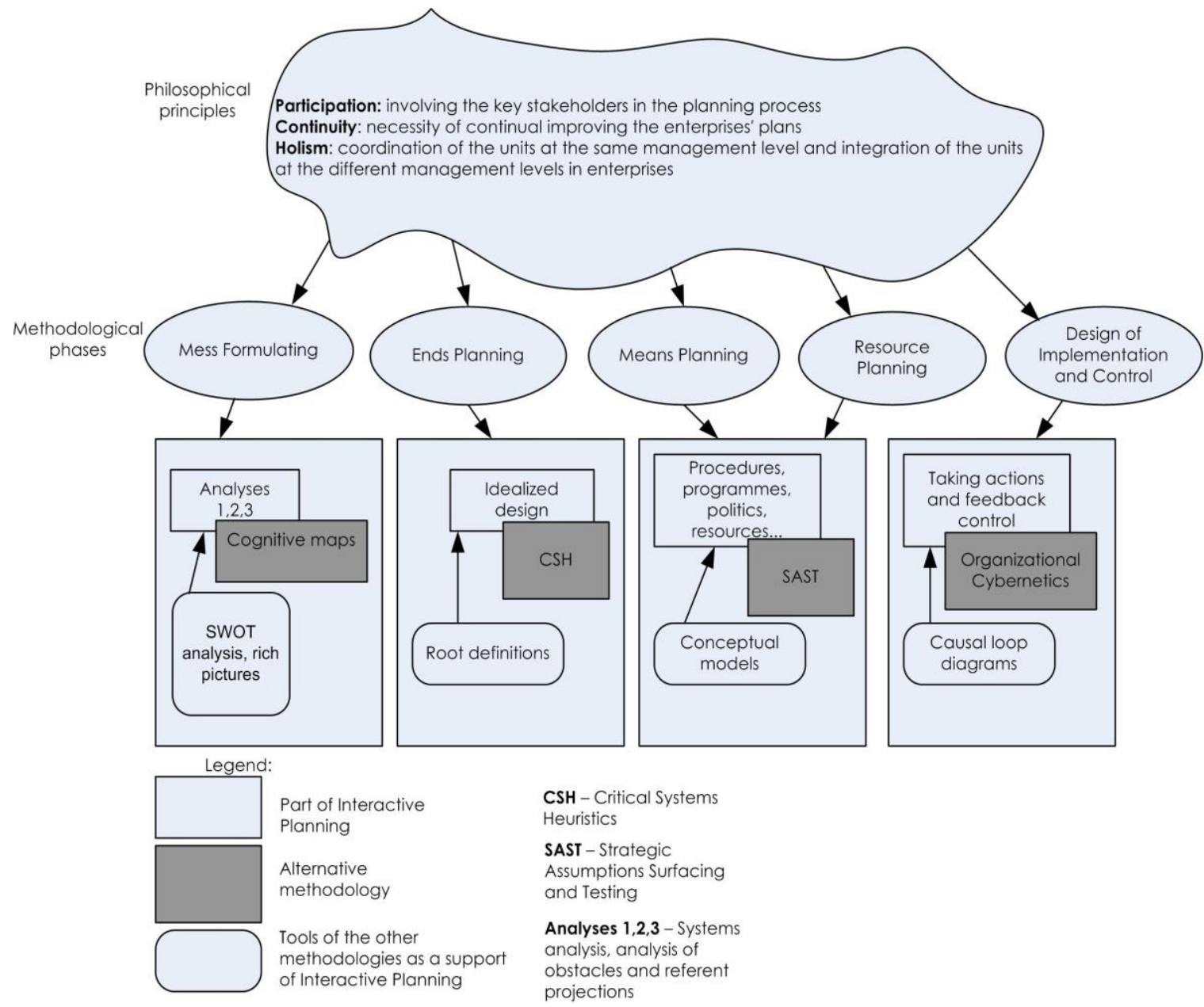

Source: Author's illustration

\section{Strengths and Limitations of Systems Methodologies' Combined Use}

The following two basic arguments support combined use of systems methodologies (Mingers, 2001): First argument refers to the multidimensionality of problem situation under consideration- material, personal and social 'worlds' - which means that different aspects of problem situations need to be addressed. If we accept only one methodology we get a constrained view of the considered problem situation. Secondly, the intervention itself is the process that has several phases - appreciation, analysis, assessment and taking action. Particular methodologies have certain strengths and limitations related to these different phases. According to Mingers (2001), other benefits of combining the systems methodologies are as follows: seeking to assess validity of data through combining different sources of data, methodologies and researchers; creativity - discovering the new factors that stimulate future research; expansion - broadening the scope of research to consider wider aspects of the situation.

However, when we combine methodologies from different paradigms we deal with certain philosophical, cultural, cognitive and practical limitations (Kotiadis and Mingers, 2006). The main philosophical limitation is paradigm incommensurability that 
figuratively could be presented on the following way: group of scientist relying on different paradigm see different things when they look from the same point in the same direction (Kuhn, 1962, p. 149 after Petrović, 2012, p. 803). Hence it can be concluded that paradigms are self-sufficient, internally referential and mutually exclusive (Bowers, 2011).

On the other side, Mingers (2001) argues several arguments against strong view of paradigm incommensurability, such as:

- Although some key features of paradigms are exclusive, there are so-called transition zones in which different paradigms can be linked.

- It is not necessary to accept that certain methodology wholly belongs to only one paradigm, but it is possible to disconnect particular method or methodology from its normal paradigm and "use it consciously and critically" within another.

- Furthermore, it is not possible to completely separate objective and subjective aspects of problem situations.

- Finally, different paradigms enable different perspectives or insights into reality that is more complex than individual systems approaches can capture. Accordingly, it is wrong to wholly accept the postulates of any one paradigm.

Cultural difficulties are related to the extent in which organizational culture and education could be obstacle for combining the methodologies, i.e. the competencies in using the different systems methodologies are very important.

Cognitive barriers can be divided into: difficulties in shifting paradigms and characteristics of personality that uses particular methodology. In fact, acquiring the new paradigm is more than acquiring the relevant knowledge, i.e. it requires active participation, experience and practice. In the same time, different persons have different preferences for using the methodologies (e.g. people who are precise, accurate and reliable will prefer using the quantitative approaches).

Following practical limitations of combining the systems methodologies can also be distinguished: combined use of systems methodologies takes more time, practitioners who do not have enough experience in using the systems methodologies, clients who think that combined use of methodologies is risky, etc.

Despite the limitations, there are numerous examples, i.e. cases studies illustrating the successful mixing the systems methodologies. Mingers (2000) provided a survey of successful combinations of systems methodologies. Also, the following fruitful combinations of systems methodologies are particularly interesting: Dialectical Systems Theory and Multi-Criteria Decision Making Methods (e.g. Čančer and Mulej, 2010), Soft Systems Methodology and System Dynamics - SSM and SD (e.g. Lane and Oliva, 1998), as well as Strategic Assumptions Surfacing and Testing - SAST and VSM (e.g. Pollalis and Dimitriou, 2008).

Munro and Mingers (2002) conducted an empirical research that had resulted in the following conclusions:

- Combining different systems methodologies in one intervention is increasingly used.

- Combined use of systems methodologies is assessed as very successful by the practitioners.

- There are relatively few combinations of hard and soft methodologies, i.e. combinations of methodologies from the same paradigm are mostly used.

- Choice of methodology depends on knowledge, experience and skills of practitioners, the nature of considered problem as well as academic and organizational context. 


\section{Conclusion}

Growing complexity and diversity of problem situations in contemporary enterprises imply using different systems approaches, i.e. systems methodologies, methods, models and techniques. They address and highlight different aspects of considered problem situation. Respecting the critical awareness as one of the key commitments of CST, one can conclude that each systems methodology have certain strengths and weaknesses which are the basis for their combined use.

Respecting the all above-mentioned, one can conclude that methodologically appropriate combined use of systems methodologies contributes to more comprehensive understanding and improvement of managing the problem situations in enterprises. The paper highlights relevant issues in contemporary systems science that is related to identifying the features, benefits and challenges in combining the systems methodologies. It is an overview of findings from previous research in this research area. The paper does not address the possibilities of combining the particular systems methodologies, e.g. SSM and SD, SSM and VSM, SAST and VSM, etc., as well as their application in enterprises. These are the relevant research limitations. Therefore, researching the combined use of certain systems methodologies and their potential application in improving the effectiveness of managing the problem situations in enterprises in the Republic of Serbia are the guidelines for future research.

\section{References}

1. Bennett, P., Ackermann, F., Eden, C., Williams, T. (1997), „Analysing Litigation and Negotiation: Using a Combined Methodology", In Mingers, J. and Gill, A. (Eds.), Multimethodology - The Theory and Practice of Combining Management Science Methodologies, Wiley, Chichester, pp. 59-87.

2. Bowers, D.T. (2011), "Towards a Framework for Multiparadigm Multimethodologies", Systems Research and Behavioral Science, Vol. 28 No. 5, pp. 537-552.

3. Čančer, V., Mulej, M. (2010) "The Dialectical Systems Theory's Capacity for Multi-Criteria Decision-Making", Systems Research and Behavioural Science, Vol. 27 No. 3, pp. 285-300.

4. Clarke, S., Lehaney, B. (2000), "Mixing Methodologies for Information Systems Development and Strategy: A Higher Education Case Study", The Journal of the Operational Research Society, Vol. 51 No. 5, pp. 542-556.

5. Jackson, M.C. (1991), "Systems methodologyfor the Management Sciences", Plenum, New York.

6. Jackson, M.C. (1994), "Critical Systems Thinking: Beyond the Fragments", System Dynamics Review, Vol. 10 No. 2/3, pp. 213-229.

7. Habermas, J. (1972), „Knowledge and Human Interests", Heinemann, London.

8. Jackson, M.C. (2001), "Critical Systems Thinking and Practice”, European Journal of Operational Research, Vol. 128 No. 2, pp. 233-244.

9. Jackson, M.C. (2003), "Systems Thinking: Creative Holism for Managers", John Wiley and Sons, New York.

10. Jackson, M.C. (2010), „Reflections on the Development and Contribution of Critical Systems Thinking and Practice", Systems Research and Behavioral Science, Vol. 27 No. 2 , pp. 133-139.

11. Kinloch, P., Francis, H., Francis, M., Taylor, M. (2009), „Supporting Crime Detection and Operational Planning with Soft Systems Methodology and Viable Systems Model", Systems Research and Behavioural Science, Vol. 26 No. 1, pp. 3-14.

12. Kotiadis, K., Mingers, J. (2006), "Combining PSMs with Hard OR Methods: The Philosophical and Practical Challenges", Journal of the Operational Research Society, Vol. 57 No. 7, pp. 856-867.

13. Kuhn, T. (1962), "The Structure of Scientific Revolutions", The 2nd Edition, The University of Chicago Press, Chicago. 
14. Lane, D., Oliva, R. (1998), "The Greater Whole: Towards a Synthesis of System Dynamics and Soft Systems Methodology", European Journal of Operational Research, Vol. 107 No.1, pp. 214-235.

15. Mingers, J. (1997a), „Towards Critical Pluralism”, In Mingers, J. and Gill, A. (Eds.), Multimethodology - The Theory and Practice of Combining Management Science Methodologies, Wiley, Chichester, pp. 1-20.

16. Mingers, J. (1997b), „Multiparadigm Multimethodology”, In Mingers, J.and Gill, A. (Eds.), Multimethodology - The Theory and Practice of Combining Management Science Methodologies, Wiley, Chichester, pp. 407-437.

17. Mingers, J. (2000), "Variety Is the Spice of Life: Combining Soft and Hard OR/MS Methods", International Transactions in Operational Research, Vol. 7 No. 6, pp. 673-691.

18. Mingers, J. (2001), "Combining IS Research Methods: Towards a Pluralist Methodology", Information Systems Research, Vol. 12 No. 3, pp. 240-259.

19. Mingers, J., Brocklesby, J. (1997), „Multimethodology: Towards a Framework for Mixing Methodologies", Omega - International Journal for Management Science, Vol. 25 No. 5 , pp. 489-509.

20. Munro, I., Mingers, J. (2002), „The Use of Multimethodology in Practice-Results of a Surwey of Practioners", Journal of the Operational Research Society, Vol. 53 No. 4, pp. 369-378.

21. Ormerod, R. (1997), "Mixing Methods in Practice: A Transformation-Competence Perspective", In Mingers, J. \& Gill, A. (Eds.), Multimethodology - The Theory and Practice of Combining Management Science Methodologies, Wiley, Chichester, pp. 29-58.

22. Petrović, S. P. (2012), "Pluralism in Structuring the Management Problem Situations", Teme, Vol. 36 No. 2, pp. 797-814.

23. Pollalis, Y.A., Dimitriou, N.K. (2008), „Knowledge Management in Virtual Enterprises: A Systemic Multi-methodology towards the Strategic Use of Information", International Journal of Information Management, Vol. 28 No. 4, pp. 305-321.

24. Schwaninger, M., Peréz Ríos, P.H. (2008), "System Dynamics and Cybernetics: A Synergetic Pair", System Dynamics Review, Vol. 24 No 2, pp. 145-174.

25. Zlatanović, D. (2015), „Metodološki aspekti kombinovanog korišćenja sistemskih metodologija u upravljanju problemskim situacijama poslovne ekonomije" (in Serbian: Methodological Aspects of Combined Use of Systems Methodologies for Managing the Problem Situations of Business Economics; Doctoral Dissertation), Faculty of Economics, University of Kragujevac, Kragujevac.

\section{About the author}

Dejana Zlatanović is an assistant on the following subjects: Economic Cybernetics and Systems Theory-Application in Business Economics, at the University of Kragujevac, Faculty of Economics, Republic of Serbia, where she received her master and PhD degrees. Her research interest focus is on systems thinking and its application in business economics. Author can be contacted at dejanaz@kg.ac.rs 